'Instituto da Saúde, Agrárias e Humanas, Centro Universitário do Planalto de Araxá (UNIARAXĀ), Av. Ministro Olavo Drumond, 05, São Geraldo, CEP 38180-900, Araxá, MG, Brasil

${ }^{2}$ Centro Universitário do Planalto de Araxá (UNIARAXÁ), Araxā, MG, Brasil

* autor correspondente $\boldsymbol{\nabla}$ diegoacmoreira@gmail.com

\title{
Efeitos de fontes nitrogenadas em consórcio com regulador de crescimento vegetal em (Phaseolus vulgaris)
}

\author{
Effects of nitrogen sources in association with plant growth \\ regulator (Phaseolus vulgaris)
}

Diego Aparecido Carvalho Moreira ${ }^{*}$, Diogo Aristóteles Rodrigues Gonçalves²,

Jorge Otavio Mendes de Oliveira Junek², David Bitencuortt Ribeiro², Ana Carolina de Paula Marques², Eudilaine Cruvinel de Almeida², Paulo Roberto Fávero de Fravet ${ }^{2}$

RESUMO: O feijoeiro comum (Phaseolus vulgaris) é uma das principais culturas produzidas no Brasil e no mundo. Sua importância extrapola o aspecto econômico por sua relevância nutricional, sendo uma importante fonte proteica. Devido à importância da cultura, o presente trabalho teve como objetivo elucidar questões referentes ao uso de reguladores de crescimento na cultura do feijoeiro, bem como os efeitos benéficos ou não da inoculação com bactérias do gênero Rhizobium. O experimento foi conduzido no Campo Experimental do Uniaraxá "Fausto de Ávila", localizado em Araxá - MG, com delineamento experimental em blocos casualizados, disposto em esquema fatorial de $2 \times 2$, descritas como fator 1 a fonte de nitrogênio (ureia e Rhizobium tropici) e fator 2 a aplicação de regulador de crescimento (aplicado ou não). Os tratamentos foram: $\mathrm{T} 1\left(50 \mathrm{Kg} \mathrm{ha}^{-1} \mathrm{de}\right.$ nitrogênio mineral), T2 (50 Kg ha ${ }^{-1}$ de nitrogênio mineral + Regulador de crescimento vegetal), T3 (Inoculação com Rhizobium tropici) e T4 (Inoculação com Rhizobium tropici + Regulador de crescimento vegetal). Os tratamentos foram dispostos em quatro blocos e avaliados os números de nódulos por planta; massa seca da parte aérea $\left(\mathrm{g} \mathrm{pl}^{-1}\right)$; massa seca da raiz $\left(\mathrm{g} \mathrm{pl}^{-1}\right)$; números de vagens $\left(\mathrm{n}^{\mathrm{o}}\right)$; peso de 100 grãos $(\mathrm{g})$; e produtividade $\left(\mathrm{Kg} \mathrm{ha}^{-1}\right)$. As fontes de nitrogênio proporcionaram resultados semelhantes entre os tratamentos, exceto para número de nódulos e massa seca da parte aérea. Em relação ao regulador de crescimento vegetal, destacaram-se os tratamentos T1 e T2 nas variáveis: números de vagens, peso de 100 grãos e produtividade $\mathrm{Kg} \mathrm{ha}^{-1}$.

PALAVRAS-CHAVE: FBN, hormônios de crescimento, simbiose, inoculação.
ABSTRACT: Common bean (Phaseolus vulgaris) is one of the main crops produced in Brazil and worldwide. Its importance goes beyond the economic aspect, due to its nutritional relevance as an important protein source. The present work aimed to elucidate questions regarding the use of growth regulators in the bean crop, as well as whether the inoculation with bacteria of the genus Rhizobium has beneficial effects or not. The experiment was conducted at the Uniaraxá Experimental Field "Fausto de Ávila", located in Araxá - MG. We used a randomized complete block design, arranged in a factorial scheme of $2 \times 2$, with the nitrogen source (urea and Rhizobium tropici) as factor 1 and the application of growth regulator (applied or not) as factor 2. The treatments were: $T 1$ (50 Kg ha ${ }^{-1}$ of mineral nitrogen), T2 (50 Kg ha-1 of mineral nitrogen + Plant growth regulator), T3 (Inoculation with Rhizobium tropici) and T4 (Inoculation with Rhizobium tropici + plant growth). The treatments were arranged in four blocks and evaluated: the numbers of nodules per plant; dry shoot mass $\left(\mathrm{g} \mathrm{pl}^{-1}\right)$; root dry mass $\left(\mathrm{g} \mathrm{pl}^{-1}\right)$; pod numbers $\left(n^{\circ}\right)$; weight of 100 grains $(\mathrm{g})$ and yield $\left(\mathrm{Kg} \mathrm{ha}^{-1}\right)$. Nitrogen sources provided similar results among treatments, except for number of nodules and shoot dry mass. As for the plant growth regulator, the treatments $T 1$ and $T 2$ were highlighted in the variables: pod numbers, weight of 100 grains and productivity $\mathrm{Kg} \mathrm{ha}^{-1}$.

KEYWORDS: FBN, growth hormones, symbiosis, inoculation. 


\section{Introdução}

$\mathrm{O}$ nitrogênio $(\mathrm{N})$ é um macronutriente essencial que o feijoeiro demanda em grandes quantidades segundo Fanceli e Dourado Neto (2007). Além do elevado custo econômico, o uso de adubos nitrogenados em solos tropicais tem ainda um custo ecológico adicional. Estima-se que as perdas de adubos nitrogenados fornecidos às plantas estão em torno de $50 \%$, sendo ocasionadas principalmente por lixiviação, na forma de nitrato e escorrimento superficial, provocada pela água das chuvas e/ou irrigação de acordo com Straliotto, Teixeira e Mercante (2002). A Rhizobium tropici destaca-se entre as espécies de bactéria mais eficientes para a fixação biológica de nitrogênio (FBN) em feijoeiro, por apresentar maior estabilidade genética e maior tolerância a temperaturas mais elevadas e acidez do solo (MARTÍNEZ-ROMERO et al., 1991).

Os reguladores são uma mistura composta por reguladores vegetais (hormônios sintéticos) e substâncias nutritivas, que em quantidades adequadas têm como finalidade modificar e influenciar de forma positiva tanto a morfologia quanto a fisiologia das plantas.

Considerando que há diferentes tecnologias em estudo para aprimorar o manejo do feijoeiro e incrementar a produtividade com o menor impacto possível ao meio ambiente e a importância dessa cultura para a alimentação diária dos brasileiros, são essenciais estudos que possam melhorar as técnicas agronômicas deste cultivo. Desta forma, o presente trabalho busca elucidar questões referentes ao uso de reguladores de crescimento na cultura do feijoeiro bem como os efeitos benéficos ou não da inoculação com bactérias do gênero Rhizobium.

\section{Material e Métodos}

O experimento foi conduzido no Campo Experimental "Fausto de Ávila" do Centro Universitário do Planalto de Araxá - UNIARAXÁ, localizado no município de Araxá, MG, situado a $19^{\circ} 34^{\prime} 45,2^{\prime \prime} \mathrm{S}$ e $46^{\circ} 57^{\prime} 15,3$ ' W, com altitude de 932 m, em um Latossolo Vermelho, eutrófico, textura média. O clima da região, segundo classificação de Köppen, é cwa (clima temperado úmido com inverno seco e verão quente).

$\mathrm{O}$ delineamento experimental utilizado foi o de blocos casualizados em esquema fatorial de $2 \times 2$, sendo o fator 1 a fonte de nitrogênio e o fator 2 a aplicação de regulador de crescimento, com quatro blocos. As fontes de nitrogênio foram adubação mineral utilizando ureia e a inoculação utilizando Rhizobium tropici, enquanto no fator 2 foi utilizado ou não o regulador de crescimento. As parcelas experimentais tiveram um dimensionamento de $3,0 \mathrm{~m} \times 3,0 \mathrm{~m}$. Totalizando assim $9 \mathrm{~m}^{2}$ por parcela. Cada parcela foi composta por seis linhas de $3,0 \mathrm{~m}$ de comprimento, espaçadas em $0,50 \mathrm{~m}$ entre linhas e 12 plantas por metro linear, totalizando um estande de 240.000 plantas por hectare.

Foi realizada a análise química do solo da área experimental, cujos valores estão descritos na Tabela 1 a seguir.

A adubação de plantio foi determinada com base na necessidade da cultura, com aplicação em todos os tratamentos descritos na Tabela 2, de $20 \mathrm{Kg} \mathrm{ha}^{-1}$ de N, $70 \mathrm{Kg} \mathrm{ha}^{-1}$ de $\mathrm{P}_{2} \mathrm{O}_{5}$ e $20 \mathrm{Kg} \mathrm{ha}^{-1}$ de $\mathrm{K}_{2} \mathrm{O}$. Em cobertura, somente os tratamentos 1 e 2 Tabela 2 receberam nitrogênio químico na dose $50 \mathrm{Kg}$ de $\mathrm{N} \mathrm{ha}^{-1}$ divididos aos 20 e 30 dias após a emergência (DAE), em duas coberturas, $56,81 \mathrm{Kg} \mathrm{ha}^{-1}$ de ureia, por cobertura.

$\mathrm{O}$ inoculante utilizado para o trabalho foi à base de turfa, recomendado para a cultura do feijão, que contém as estirpes de Rhizobium tropici (Semia 4077/ Semia 4088), com concentração bacteriana 3,0x109 UFC/g, utilizando a dose recomendada pelo fabricante que é $2 \mathrm{~g} \mathrm{Kg}^{-1}$ de semente.

$\mathrm{O}$ regulador de crescimento vegetal utilizado foi à base de ácido indolbutírico (auxina) $0,005 \%$, cinetina (citocinina) $0,009 \%$ e ácido giberélico (giberelina) $0,005 \%$, utilizando a dose recomendada pelo fabricante no tratamento de sementes, que é 7,5 $\mathrm{mL} \mathrm{Kg}^{-1}$ de semente.

Desta forma, formaram-se os seguintes tratamentos expressos na Tabela 2 a seguir.

A semeadura ocorreu no dia 29 de outubro de 2016. A cultivar utilizada no experimento foi a BRS Estilo, que é uma cultivar de feijoeiro comum do grupo comercial carioca e apresenta arquitetura de planta ereta, adaptada à colheita mecânica direta. Apresenta alto potencial produtivo e estabilidade de produção. A BRS Estilo, em relação a doenças, é moderadamente resistente à antracnose e ferrugem, apresenta resistência intermediária ao crestamento bacteriano comum e à ferrugem e é suscetível à mancha angular, mosaico dourado e murcha de fusarium.

No estádio R6 da cultura (Floração), foram avaliadas as seguintes variáveis: a) número de nódulos por planta; b) massa seca da parte aérea $\left(\mathrm{g} \mathrm{pl}^{-1}\right)$; c) massa seca da raiz $\left(\mathrm{g} \mathrm{pl}^{-1}\right)$. $\mathrm{Na}$ colheita estádio R9 (quando a primeira vagem começa a descolorir ou secar), foram avaliados: d) números de vagens; e) peso de 100 grãos (g); f) produtividade de grãos em $\mathrm{Kg} \mathrm{ha}^{-1}$.

Para realizar a contagem do número de nódulos, foram coletadas 5 plantas e solo da rizosfera por tratamento, as massas secas da parte aérea e da raiz, que foram obtidas após secagem em estufa por 24 horas, à temperatura de $100{ }^{\circ} \mathrm{C}$.

Para determinação do número de vagens, foram coletadas 10 plantas na área útil de cada parcela. Após a contagem, debulharam-se as vagens para determinar o peso de 100 grãos através de médias de três amostragens de 100 grãos por parcela experimental. Para obtenção da produtividade de grãos, foi colhida toda a área útil das parcelas experimentais em que foi extrapolado o peso de grãos obtidos para $\mathrm{Kg} \mathrm{ha}^{-1}$ ( $13 \%$ umidade).

Tabela 1. Análise química do solo da área experimental.

\begin{tabular}{|c|c|c|c|c|c|c|c|c|c|c|c|}
\hline \multirow{2}{*}{$\begin{array}{c}\mathbf{p H} \\
\mathrm{H}_{2} \mathrm{O}\end{array}$} & \multicolumn{2}{|c|}{$\mathrm{mg} / \mathrm{dm}^{3}$} & \multicolumn{7}{|c|}{$\mathrm{Cmol}_{\mathrm{c}} / \mathbf{d m}^{3}$} & \multicolumn{2}{|c|}{$\%$} \\
\hline & $\mathbf{P}$ & $\mathbf{K}$ & Al & $\mathrm{Ca}$ & Mg & $\mathbf{H}+\mathbf{A l}$ & SB & $t$ & $\mathbf{T}$ & $\mathbf{V}$ & $\mathbf{m}$ \\
\hline 6,26 & 21,97 & 209,0 & 0,02 & 1,92 & 0,66 & 2,15 & 3,11 & 3,13 & 5,26 & 59,21 & 0,64 \\
\hline
\end{tabular}

$\mathrm{H}_{2} \mathrm{O}$ : Água, P: Fósforo, K: Potássio, Al: Alumínio, Ca: Cálcio, Mg: Magnésio, H+Al: Acidez potencial, SB: Soma de bases, t: CTC efetiva, T: CTC a pH 7.0, V: Saturação por bases, m: Saturação por alumínio. 
As análises estatísticas foram realizadas submetendo os dados às pressuposições. Quando necessário, foram realizadas transformações e, posteriormente, submetidas ao teste de Tukey. Os softwares utilizados foram IBM SPSS statistics $20 \mathrm{e}$ Sisvar 5.6.

\section{Resultados e Discussão}

Para o teste de normalidade de Shapiro-Wilk, podemos observar, através da Figura 1, que os dados apresentados para a massa seca da raiz e da parte aérea não atenderam à pressuposição de normalidade, tendo uma distribuição dos dados sem confiabilidade para realizar os testes de comparações de médias, o que pode ser justificado pela metodologia de avaliação realizada com coleta das raízes das plantas a campo. Apesar de o erro de avaliação ser padronizado para o todo, pois a coleta foi realizada por mais de uma pessoa, o que desarmonizou o erro, não tornando possível a realização das análises de variância, os dados de massa seca da parte aérea não apresentaram homogeneidade, não atendendo a esta pressuposição, o que dificulta a confiabilidade dos dados. Mesmo não apresentando essa homogeneidade, ainda assim os dados são compatíveis com os de Pelegrin et al. (2009), Silva (2004) e Binotti (2009), que também confirmam esse maior desenvolvimento da massa seca da parte aérea quando realizada adubação química tendo em vista a fixação biológica de nitrogênio.

Tabela 2. Descrição dos tratamentos.

\begin{tabular}{|c|c|}
\hline TRATAMENTO & DESCRIÇÃO \\
\hline T1 & $50 \mathrm{Kg} \mathrm{ha}^{-1}$ de nitrogênio mineral \\
\hline T2 & $50 \mathrm{Kg} \mathrm{ha}^{-1}$ de nitrogênio mineral $+\mathrm{RCV}^{*}$ \\
\hline T3 & Inoculação com Rhizobium tropici \\
\hline T4 & Inoculação com Rhizobium tropici + RCV \\
\hline
\end{tabular}

*RCV: Regulador de crescimento vegetal.
Utilizou-se o teste de Levene que, segundo Almeida, Elian e Nobre (2008), é importante para a comparação de variâncias de grupos de observações provenientes de distribuições contínuas e não necessariamente normais. É robusto à não normalidade, apesar de que algumas carências foram destacadas por alguns autores, que também apresentaram algumas opções mais eficientes. $\mathrm{O}$ teste $\mathrm{F}$ obtido através da análise de variância com um fator para comparar médias de populações normais independentes apresenta desvios no que tange ao tamanho do teste quando os grupos possuem variâncias populacionais diferentes.

Dos dados apresentados na Tabela 3, como esperado, o número de nódulos foi superior com a inoculação. Silva et al. (2012) justificam tal fato pela maior disponibilização de células de rizóbios selecionados fornecidos via inoculante, gerando vantagem na competição de infecção pelos rizóbios nativos, em contraposição à adubação química sem inoculante. $\mathrm{O}$ cultivar de feijão utilizado já foi destacado em outros trabalhos como

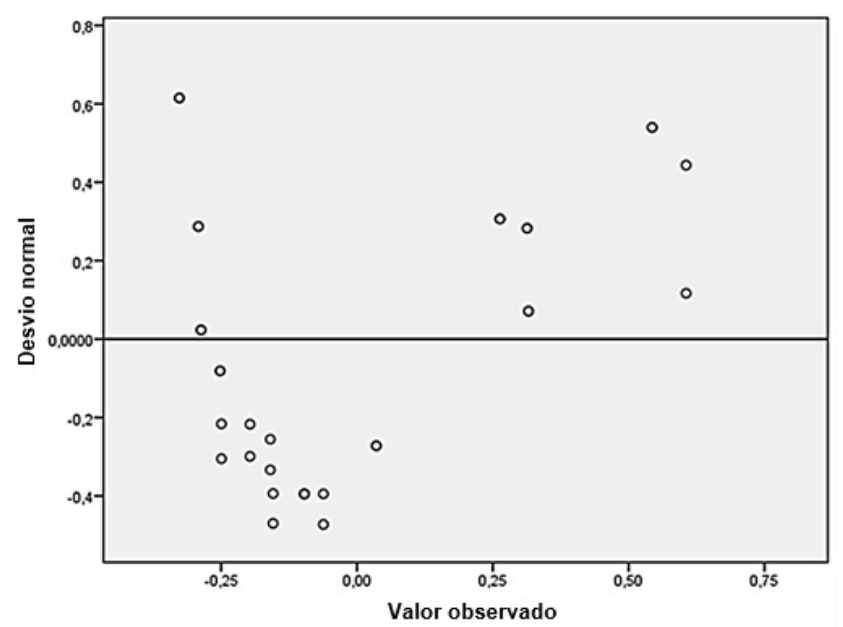

Figura 1. Scores de dispersão de normalidade da massa seca da raiz pelo teste de Shapiro-Wilk a 0,05 de probabilidade.

Tabela 3. Influência dos reguladores de crescimento na nutrição nitrogenada, via mineral e biológica, para número de nódulos, massa seca da parte aérea $\left(\mathrm{g} \mathrm{pl}^{-1}\right)$ e massa seca da raiz $\left(\mathrm{g} \mathrm{pl}^{-1}\right)$, no município de Araxá - MG.

\begin{tabular}{|c|c|c|c|c|c|c|c|}
\hline \multirow{3}{*}{$\frac{\text { Fonte de } \mathbf{N}}{\text { 离 }}$} & \multirow{2}{*}{$\begin{array}{c}\text { Regulador } \\
-\end{array}$} & \multicolumn{2}{|c|}{ Número de nódulos ( $\mathrm{n}^{\circ}$ ) } & \multicolumn{2}{|c|}{ Massa seca da parte aérea $\left(\mathrm{g} \mathrm{pl}^{-1}\right)$} & \multicolumn{2}{|c|}{ Massa seca da raiz $\left(\mathrm{g} \mathrm{pl}^{-1}\right)$} \\
\hline & & 4,25 & bA & 6,09 & $\mathbf{a A}$ & 1,17 & $\mathbf{a A}$ \\
\hline & + & 9,25 & bA & 6,99 & $\mathbf{a A}$ & 1,23 & $\mathbf{a A}$ \\
\hline \multirow{5}{*}{ 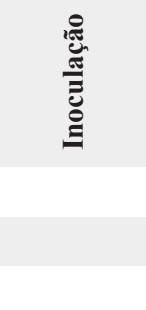 } & - & 38,00 & $\mathbf{a A}$ & 4,00 & bA & 0,93 & $\mathbf{a A}$ \\
\hline & + & 41,25 & $\mathbf{a A}$ & 4,43 & bA & 1,14 & $\mathbf{a A}$ \\
\hline & $\mathrm{CV} \%$ & \multicolumn{2}{|c|}{$24,70^{1}$} & \multicolumn{2}{|c|}{$21,12^{2}$} & \multicolumn{2}{|c|}{$33,02^{3}$} \\
\hline & W & 0,91 & $(0,02)^{* *}$ & 0,90 & $(0,03)^{* *}$ & 0,91 & $\mathbf{0 , 0 0 ^ { \text { ns } }}$ \\
\hline & $F$ & 2,37 & $(0,09)^{*}$ & 5,99 & $(\mathbf{0 , 0 0})^{\mathrm{ns}}$ & 1,17 & $(0,34)^{*}$ \\
\hline
\end{tabular}

Letras minúsculas expressam significância entre as fontes de $\mathrm{N}$ e as letras maiúsculas representam as variações significativas entre os tratamentos com regulador específico para cada fonte de $\mathrm{N}$, pelo teste de Tukey a 0,05 de probabilidade. ${ }^{1}=$ Coeficiente de variação para os dados transformados em ARCSEN $\sqrt{ }(\mathrm{X} / 100) ;{ }^{2}=$ Coeficiente de variação para os dados transformados de $\mathrm{X}=1 / \mathrm{X} ;{ }^{3}=$ Coeficiente de variação para os dados transformados de $\mathrm{X}=\mathrm{LOG}(\mathrm{X}) ; \mathrm{CV} \%$ = Coeficiente de variação; W: Teste de Shapiro-Wilk; ${ }^{1} \mathrm{~F}$ : Teste de Levene; ns: Não significativo; *: Expressa significância a 0,05 \% de probabilidade; **: Expressa significância a $0,01 \%$ de probabilidade. 
de boa resposta à nodulação e fixação de N Dias (2017). Foi constatada também a presença de nódulos no tratamento químico sem inoculante, indicando a ocorrência de estirpes nativas no solo, visto que a nodulação foi baixa. Fullin et al. (1999) e Vieira, Tsai e Teixeira (2005) demonstram em sua pesquisa a possibilidade dessa presença de populações nativas de Rhizobium nos solos. Pelegrin et al. (2009), avaliando diversas doses de fertilizantes minerais nitrogenados $\left(0,20,40,80\right.$ e $160 \mathrm{Kg} \mathrm{ha}^{-1}$ de $\mathrm{N}$ como ureia) na cultura do feijoeiro, cv. Pérola, além de controles com inoculação de Rhizobium tropici combinada ou não com aplicação de $20 \mathrm{Kg} \mathrm{ha}^{-1}$ de $\mathrm{N}$, demonstraram que, embora a nodulação das plantas não tenha sido alterada pelos tratamentos, verificaram redução conforme o aumento da dose de $\mathrm{N}$ aplicada, pois a adubação química inibe o processo de simbiose entre a planta e bactéria para FBN

Com relação à massa seca da parte aérea, os dados apresentaram maior quantidade quando realizada a adubação química. Binotti (2009) também verificaram efeito positivo com a aplicação de nitrogênio com ou sem uso de regulador. Esse aumento é resultado da maior disponibilidade de $\mathrm{N}$ para a planta do feijão, ocorrendo assim um incremento em sua absorção e, como consequência, maior produção de massa seca, pois o nitrogênio tem influência direta na fotossíntese e crescimento da planta, sendo parte integrante da molécula de clorofila (SILVA, 2004).

Com relação à massa seca da raiz, Castro, Cato e Vieira (2005) observaram que a utilização de regulador à base de auxina, citocinina e giberelina incrementou a massa seca das raízes de feijoeiro até a concentração de $10 \mathrm{~mL} \mathrm{Kg}^{-1}$ de semente e Vieira \& Castro (2001), testando em arroz, obteve incrementos significativos para este parâmetro. Quanto maior a concentração de auxina, maior a taxa de crescimento do sistema radicular segundo Kudoyarova, Farkhutdinov e Veselov (1997) e o ácido indolbutírico tem a capacidade de promover a formação de primórdios radiculares. Por esse motivo, tem sido utilizado para provocar e acelerar o enraizamento de estacas na propagação vegetativa de numerosas espécies vegetais, ou seja, esse regulador é utilizado para favorecer a rizogênese (COLL et al., 2001).

Dos dados apresentados na Tabela 4, com relação ao número de vagens, a inoculação e a adubação química não apresentam diferenças, porém, quando se observa a adubação química com utilização do regulador de crescimento vegetal, há uma quantidade maior por planta. Na cultura da soja, Bertolin et al. (2010) observaram que o uso de regulador de crescimento proporcionou incremento no número de vagens por planta e na produtividade de grãos de soja, tanto em aplicação via sementes quanto via foliar. Oliveira, Pace e Rosolem (1998), avaliando a aplicação de reguladores em diversas épocas, associadas ou não à aplicação do produto nas sementes de feijão, constataram efeito significativo no número de vagens por planta somente quando realizado o tratamento das sementes, porém, quando realizada aplicação foliar, não puderam associar o efeito da giberelina ou citocinina à produção de vagens de feijão.

A variável peso de 100 grãos, por também ser uma característica de produtividade, apresentou maior peso dos grãos quando fornecidos hormônios que auxiliam no melhor desenvolvimento da planta com adubação química com maior aceleração no metabolismo da planta. Em vista da inoculação, Rodrigues e Fioreze (2015) ainda finaliza dizendo, em seu trabalho "Efeito de reguladores aplicados com adubação química ou bactérias fixadoras", que seu efeito de biorregulação proporcionado pela simbiose pode substituir aqueles proporcionados pela aplicação de estimulantes comerciais ou mesmo atuar de forma sinérgica.

Com relação à produtividade em $\mathrm{Kg} \mathrm{ha}^{-1}$, houve diferença apenas quando realizada adubação química associada ao regulador de crescimento vegetal, enquanto a inoculação não apresentou diferença quanto à utilização de regulador ou não, o que já e um conceito da aplicação de produtos como reguladores de crescimento. Leite, Rosolem e Rodrigues (2003) mencionaram que, quando aplicado, o ácido giberélico induz a um crescimento vegetativo intenso em diversas culturas, maior do que o necessário para a máxima produtividade, como a inoculação e um processo biológico que visa um desenvolvimento com

Tabela 4. Influência dos reguladores de crescimento na nutrição nitrogenada, via mineral e biológica para número de vagens, peso de 100 grãos ( $\mathrm{g}$ ) e produtividade $\left(\mathrm{Kg} \mathrm{ha}^{-1}\right)$, no município de Araxá - MG.

\begin{tabular}{|c|c|c|c|c|c|c|c|}
\hline \multirow{3}{*}{$\frac{\text { Fonte de N }}{\text { N }}$} & \multirow{2}{*}{$\begin{array}{c}\text { Regulador } \\
-\end{array}$} & \multicolumn{2}{|c|}{ Número de vagens $\left(\mathrm{n}^{0}\right)$} & \multicolumn{2}{|c|}{ Peso de 100 grãos (g) } & \multicolumn{2}{|c|}{ Produtividade $\left(\mathrm{Kg} \mathrm{ha}^{-1}\right)$} \\
\hline & & 14,25 & $\mathbf{a B}$ & 15,66 & $\mathbf{a B}$ & 2031,12 & $\mathbf{a B}$ \\
\hline & + & 17,62 & $\mathbf{a A}$ & 16,28 & $\mathbf{a A}$ & 2844,31 & $\mathbf{a A}$ \\
\hline \multirow{5}{*}{ 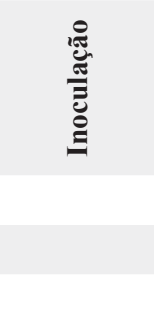 } & - & 15,62 & $\mathbf{a A}$ & 16,26 & $\mathbf{a A}$ & 2124,20 & $\mathbf{a A}$ \\
\hline & + & 17,50 & $\mathbf{a A}$ & 16,38 & $\mathbf{a A}$ & 2742,60 & $\mathbf{a A}$ \\
\hline & $\mathrm{CV} \%$ & \multicolumn{2}{|c|}{$16,45^{1}$} & \multicolumn{2}{|c|}{$3,57^{2}$} & \multicolumn{2}{|c|}{$2,85^{3}$} \\
\hline & W & 0,93 & $0,18 *$ & 0,93 & $0,02 * *$ & 0,94 & $0,12 *$ \\
\hline & ${ }^{\prime} F$ & 1,06 & $(0,38)^{*}$ & 2,96 & $(0,05) *$ & 0,77 & $(0,52) *$ \\
\hline
\end{tabular}

Letras minúsculas expressam significância entre as fontes de $\mathrm{N}$ e as letras maiúsculas representam as variações significativas entre os tratamentos com regulador específico para cada fonte de $\mathrm{N}$, pelo teste de Tukey a 0,05 de probabilidade. ${ }^{1}=$ Coeficiente de variação para os dados transformados em $\mathrm{ARCSEN} \sqrt{ }(\mathrm{X} / 100)$; ${ }^{2}=$ Coeficiente de variação para os dados transformados de $\mathrm{X}=1 / \mathrm{X} ;{ }^{3}=$ Coeficiente de variação para os dados transformados de $\mathrm{X}=\mathrm{LOG}(\mathrm{X}) ; \mathrm{CV} \%=\mathrm{Coeficiente}$ de variação; W: Teste de Shapiro-Wilk; ' $\mathrm{F}$ : Teste de Levene; *: Expressa significância a 0,05 \% de probabilidade; **: Expressa significância a 0,01 \% de probabilidade. 
maior sanidade. Ele não chega a proporcionar condições para maior potencial produtivo para a planta, enquanto a adubação química fornece um ambiente propício para a maior expressão do seu potencial produtivo e, quando associado ao regulador de crescimento vegetal, esse potencial consegue agregar maior expressão à adubação química, mostrando assim que adubação química com regulador de crescimento vegetal chegou a produzir $813,19 \mathrm{Kg} \mathrm{ha}^{-1}$ a mais do que quando não aplicado regulador, porém, no quesito adubação química e inoculação com relação à produtividade, não houve diferenças na avaliação entre fontes de nitrogênio.

Esses resultados são semelhantes àqueles obtidos por Moraes et al. (2010) e indicam a possibilidade de cultivo do feijoeiro sem a necessidade de aplicação de adubos nitrogenados. O que está de acordo com Pelegrin et al. (2009) que observaram que a adubação com $20 \mathrm{Kg} \mathrm{ha}^{-1}$ de $\mathrm{N}$ acrescida de inoculante com a estirpe de Rhizobium tropici CIAT 899 possibilitou a obtenção de rendimento de grãos na cultura de feijoeiro equivalente à aplicação de até $160 \mathrm{Kg}^{-1} \mathrm{ha}^{-1} \mathrm{~N}$ e que a inoculação, acrescida da adubação com $20 \mathrm{Kg} \mathrm{ha}^{-1}$ de $\mathrm{N}$ no plantio, propiciou incremento de receita líquida semelhante à aplicação de $160 \mathrm{Kg} \mathrm{ha}^{-1}$ de $\mathrm{N}$ e superior ao tratamento com a adubação de $20 \mathrm{Kg} \mathrm{ha}^{-1}$ de $\mathrm{N}$ sem o uso do inoculante.

\section{Conclusão}

Nas condições do presente trabalho, a inoculação do feijoeiro e adubação mineral nitrogenada proporcionaram resultados semelhantes entre os tratamentos para massa seca da raiz, números de vagens, peso de 100 grãos e produtividade, exceto para número de nódulos e massa seca da parte aérea.

Em relação ao regulador de crescimento vegetal, destacaram-se os tratamentos de $50 \mathrm{Kg} \mathrm{ha}^{-1}$ de nitrogênio mineral e de $50 \mathrm{Kg} \mathrm{ha}^{-1}$ de nitrogênio mineral + Regulador de crescimento vegetal para as variáveis: número de vagens, peso de 100 grãos e produtividade.

\section{Referências}

ALMEIDA, A.; ELIAN, S.; NOBRE, J. Modificações e alternativas aos testes de Levene e de Brown e Forsythe para igualdade de variâncias e médias. Revista Colombiana de Estadística, Bogotá, v. 31, n. 2, p. 241-260, 2008.

BERTOLIN, D. C. et al. Aumento da produtividade de soja com a aplicação de bioestimulantes. Bragantia, Campinas, v. 69, n. 2, p. 339-347, 2010. http://dx.doi.org/10.1590/S0006-87052010000200011.

BINOTTI, F. F. S. Manejo do nitrogênio no feijoeiro de inverno em sucessão a milho e Brachiaria em sistema plantio direto. 2009. $178 \mathrm{f}$. Tese (Doutorado)-Faculdade de Engenharia, Universidade Estadual Paulista, Ilha Solteira, 2009.

CASTRO, P. R. C.; CATO, S. C.; VIEIRA, E. L. Biorreguladores e bioestimulantes em feijoeiro. In: FANCELLI, A. L.; DOURADONETO, D. (Ed.). Feijão irrigado: tecnologia \& produção. Piracicaba: ESALQ, 2005. p. 54-62.

COLL, J. B. et al. Fisiologia vegetal. Madrid: Ediciones Pirámide, 2001. 566 p.

DIAS, P. A. S. Potencial genético de linhagens elite de feijoeirocomum para fixação biológica de nitrogênio. 2017. $111 \mathrm{f}$. Tese
(Doutorado em Genética e Melhoramento de Plantas)-Escola de Agronomia, Universidade Federal de Goiás, Goiânia, 2017.

FANCELI, A. L.; DOURADO NETO, D. Produção de feijão. 2. ed. Piracicaba: Livroceres, 2007. 386 p.

FULLIN, E. A. et al. Nitrogênio e molibdênio na adubação do feijoeiro irrigado. Pesquisa Agropecuária Brasileira, Brasília, v. 34, n. 7, p. 1145-1149, 1999. http://dx.doi.org/10.1590/S0100204X1999000700005.

KUDOYAROVA, G. R.; FARKHUTDINOV, R. G.; VESELOV, S. Y. Comparison of the effects of nitrate and ammonium forms of nitrogen on auxin content in roots and the growth of plants under different temperatures. Plant Growth Regulation, Dordrecht, v. 23, n. 3, p. 207-208, 1997. http://dx.doi.org/10.1023/A:1005990725068.

LEITE, V. M.; ROSOLEM, C. A.; RODRIGUES, J. D. Gibberellin and cytokinin effects on soybean growth. Scientia Agrícola, Piracicaba, v. 60, n. 3, p. 537-541, 2003. http://dx.doi.org/10.1590/ S0103-90162003000300019.

MARTÍNEZ-ROMERO, E. et al. Rhizobium tropici, a novel species nodulating Phaseolus vulgaris L. beans and Leucaena sp. trees. International Journal of Systematic Bacteriology, Reading, v. 41, n. 3, p. 417-426, 1991. http://dx.doi.org/10.1099/00207713-41-3-417.

MORAES, W. B. et al. Avaliação da fixação biológica do nitrogênio em genótipos de feijoeiros tolerantes a seca. Idesia, Arica, v. 28, n. 1, p. 61-68, 2010.

OLIVEIRA, R. F.; PACE, L.; ROSOLEM, C. A. Produção e estado nutricional do feijoeiro em função da aplicação de um promotor de crescimento. Científica, Jaboticabal, v. 26, n. 1-2, p. 203-212, 1998.

PELEGRIN, R. et al. Resposta da cultura do feijoeiro à adubação nitrogenada e à inoculação com rizóbio. Revista Brasileira de Ciência do Solo, Viçosa, v. 33, n. 1, p. 219-226, 2009. http://dx.doi. org/10.1590/S0100-06832009000100023.

RODRIGUES, J. D.; FIOREZE, S. L. Reguladores são, para muitos cultivos, indispensáveis ao alcance de bons níveis. Visão Agrícola, Piracicaba, n. 13, p. 35-39, 2015.

SILVA, M. F. et al. Nodulação e eficiência da fixação do N2 em feijão-caupi por efeito da taxa de inoculo. Revista Brasileira de Ciência do Solo, Viçosa, v. 36, n. 5, p. 1418-1425, 2012.

SILVA, M. G. Manejo do solo e adubação nitrogenada em feijoeiro de inverno. Scientia Agrícola, Piracicaba, v. 61, n. 3, p. 307-312, 2004. http://dx.doi.org/10.1590/S0103-90162004000300012.

STRALIOTTO, R.; TEIXEIRA, M. G.; MERCANTE, F. M. Fixação biológica de nitrogênio. In: AIDAR, H.; KLUTHCOUSKI, J.; STONE, L. F. (Ed.). Produção de feijoeiro comum em várzeas tropicais. Santo Antônio de Goiás: Embrapa Arroz e Feijão, 2002. p. 122-153.

VIEIRA, E. L.; CASTRO, P. R. C. Ação de bioestimulante na germinação de sementes, vigor de plântulas, crescimento radicular e produtividade de soja (Glicine max), feijoeiro (Phaseolus vulgaris L.) e arroz (Oryza sativa L.). Revista Brasileira de Sementes, Brasília, v. 23, n. 2, p. 222-228, 2001. http://dx.doi.org/10.17801/0101-3122/ rbs.v23n2p222-228.

VIEIRA, R. F.; TSAI, S. M.; TEIXEIRA, M. A. Nodulação e fixação simbiótica de nitrogênio em feijoeiro com estirpes nativas de rizóbio, em solo tratado com lodo de esgoto. Pesquisa Agropecuária Brasileira, Brasília, v. 40, n. 10, p. 1047-1050, 2005. http://dx.doi. org/10.1590/S0100-204X2005001000015.

Recebido: 13 jul. 2017 Aprovado: 07 fev. 2018 